Original Research Article

\title{
Preparation and characterization of Acrylic Emul- sion paints formulated from nano-emulsion of Methyl-Metacrylate/ Butyl Acrylate
}

Singh, Jaspal; Chawla, Malvika and Kaushik, R.D.

Department of Chemistry, Gurukul Kangri Vishwavidyalya, Haridwar, Uttarakhand, India

Corresponding Author: sjs2874@yahoo.com

\section{A R T I C L E I N F O}

Received: 27 January 2018 | Accepted: 22 April 2018 | Published Online: 15 August 2018

DOI: $10.31786 / 09756272.18 .9 .1 .108$

EOI: 10.11208/essence.18.9.1.108

Article is an Open Access Publication.

This work is licensed under Attribution-Non Commercial 4.0 International

(https://creativecommons.org/licenses/by/4.0/)

CThe Authors (2018). Publishing Rights @ MANU_ICMANU \& ESSENCE_IJERC.

\section{A B S T R A C T}

Emulsion paints were formulated using acrylic polymer emulsion in the presence of Ammonium persulfate, tert. Dodecyl mercaptan, Potassium persulfate, anionic Dioctyl sulfosuccinate as surfactant and aerosol. The emulsion polymerization of acrylics with $\mathrm{NaCN}$ cellulose as protective colloid was used as binders for gloss paints of special rheological behavior. The work has shown that there was a good compatibility between the pigment and the binder during the paint formulation, which accounts for the deep colour and good opacity for paints formulated. The formulated paints were characterized for physico-chemical properties such as viscosity, hot box stability, gloss, gloss retention, opacity, scrub resistance, colour, adhesion etc., which yielded positive results, and revealed that the paints could be used as both indoor and outdoor coatings.

\section{K E Y W O R D S}

Emulsion paint | Polymerization | Acrylate emulsion | Rheological properties

\section{I T A T I O N}

Singh, Jaspal; Chawla, Malvika and Kaushik, R.D. (2018): Preparation and Characterization of Acrylic Emulsion Paints Formulated From Nano-Emulsion Of Methylmetacrylate/ Butyl Acrylate. ESSENCE Int. J. Env. Rehab. Conserv. IX (1): 55-60. 
$\begin{array}{llllllllllll}\mathbf{l} & \mathbf{n} & \mathbf{t} & \mathbf{r} & \mathbf{0} & \mathbf{d} & \mathbf{u} & \mathbf{c} & \mathbf{t} & \mathbf{i} & \mathbf{0} & \mathbf{n}\end{array}$

Emulsion paint consists of tiny polymer particles within which the pigments are trapped. The particles are suspended in water, then as the paint dries the particles fuse together, creating a film of paint on the wall. Once this happens the polymer can't be resuspended in water,Once this happens the polymer can't be resuspended in water, which is why you can't wash water-based emulsion paint back off the wall once it has dried. Emulsion house paint is a water based paint principally used for internal and external surface coatings, mostly in buildings for appearance and protection. The constituents generally used for the production of emulsion house paints includes; prime pigments, solvents, extenders, pigments, binders and additives (Abdulsalam and Yahaya, 2010). The pigments give the paint its colour, solvents make it easier to apply, resins help it dry, and additives serves as everything from fillers and so on. Today, paints are used for interior and exterior house paintings, boats, automobiles, planes, appliances, furniture, and many other places where protection and appeal are desired. However, conventional emulsion paints often lead to the crack of basal wall surface, which has an influence on the practicability and functionality of emulsion paints.

Acrylate emulsions are widely used in preparing emulsion paints owing to their good water resistance, weather resistance, ageing resistance and flexibility at low temperature (Aggarwal et. al., 2007; Alexander and Napper, 1971). Selfcrosslinked acrylate emulsions can be prepared via molecular design when some functional groups are introduced into molecular chain of polymer (Candau, 1999; Capek, 1999; Chern, 2002; Chern, 2003; Chu and Lin, 1992; Emelie et. al., 1985; Fu and You-nian, 1998; Gan et. al., 1993; Leonardi et. al., 2005; Li and Brooks, 1992; Li-jun et. al., 2008; Moriguchi et. al., 1999; Nomura et. al., 2005; Poehlein and Dougherty, 1977; Tian-ying et. al., 2005; Tian-ying et. al., 2006; Ugelstad and Hansen, 1976). Conventional soft acrylic binders, having a single, low Tg polymer type, normally produce tacky films and the formulated paints lack on blocking, dirt pickup resis- tance, surface hardness and film cohesion. One strategy to enhance the application properties of a binder is the introduction of crosslinking discussed below. Compared with cross-linked and cured methods of external cross-linked agent, self linkage has many merits such as high degree of cross-linkage and convenience of use (Vanderhoff, 1985; Wang et. al., 1994; Yan-jun et. al. 2003).

\section{Experimental}

\section{Raw Material}

Freshly prepared self-cross linked acrylate emulsion by using Butyl acrylate (BA), methyl methacrylate (MMA) and methacrylic acid (MAA) were distilled under reduced pressure to remove the polymerization inhibitor before use. Potassium persulfate (KPS, Sigma-Aldrich) was recrystallized from water. Sodium dodecyl sulfate (SDS, Fisher), Titanium oxide (Sigma-Aldrich), Ammonium hydroxide (E.Merk) N-methylol acrylamide (NMA, Sigma-Aldrich), hexadecane (HD, Sigma-Aldrich, 99\%), and $\mathrm{NaHCO}_{3}$ (E.Merk), ammonia water (E.Merk), methacrylic acid (Sigma-Aldrich), N-hydroxymethyl acrylamide (Sigma-Aldrich), poly sodium maleate were used. All the chemicals and reagents used were of analytical grade. Deionized water was used for preparation of the solutions.

\section{Method}

The paint has two components, one is binder and other is mill base, which contain pigment, extender, surfactant, thickener and other required ingredients. The preparation of paint depends upon the solid content of the binder and percentage of PVC (pigment volume concentration) of mill base.

The paint was prepared with 40\% PVC mill base, and $50 \%$ solid content of binder. Taking 33 part of the binder, which was dispersed into 67 parts of mill base with high speed stirring for $15 \mathrm{~min}$ to complete dispersion. The 40\% PVC (pigment volume concentration) mill base was prepared in Atraitor by the given method:

Step 1: The dispersing agent (240g) completely mixed in $100 \mathrm{~g}$ deionized water. The surfactant, deformer and antifungisides were added stepwise 
in dispersing agent with throughout agitation.

Step 2: $2000 \mathrm{~g}$ pigment $\left(\mathrm{TiO}_{2}\right)$ and $880 \mathrm{~g}$ of extender were kept separately.

Step 3: The material of Step 1 and Step 2 were charged slowly in atraitor by further addition of water. The machine was continued for 2 hours. After 2 hours benzyl alcohol and water was added slowly, discharging the material from atraitor. The discharged material was weighed, further ammonia (0.3 part) and water (8.5 part) was added slowly with stirring. The thickener ( 0.2 part $)$ and water (6.0 part) was also added and kept aside for about an hour.

\section{Characterization}

1. Viscosity: Viscosity of the paint was meaured by Rotothinner. The torque produced when the paddle is rotated in the sample under test is transferred to the base, via the sample container, which revolves against a torsion spring giving a direct reading in poise.

2. Hot Box Stability: Finished paint was kept in the oven at $60{ }^{\circ} \mathrm{C}$ for one month. The difference in initial and final viscosity gives the idea of accelerated storage stability.

3. Gloss at $85{ }^{\circ} \mathrm{C}$ head: The gloss of paints was directly measured by glossometer at $85^{\circ} \mathrm{C}$ head. Fine particle size emulsion has greater gloss and clarity than coarse particle size emulsions. This is caused by improved coalescence and film integration because the particle packs more closely in the resin film.

4. Gloss retention: Gloss retention was calculated by using given formula:

5. Gloss retention: (Gloss after 10 days $X$ 100) / Initial Gloss

6. Opacity: Paint was applied on the sheen opacity panel and rating was done accordingly.

7. Scrub resistance: Paint was applied on primed glass plate. The scrub was rested using the sheen machine after drying at room temperature for 7 days.

8. Colour acceptance: The depth of the blue colour was visually compared using $2 \%$ phthalo blue paint weight bases and rating was given accordingly.

9. Block resistance: Paint was applied to card and allowed to dry for two days. The painted panel was kept unfolded at $30^{\circ} \mathrm{C}$ with an average weight of $10 \mathrm{~kg}$ for 4 hours. The panel was then opened to check for stickiness, maximum rating was given for non-stickiness.

10. Adhesion: It is one of the most important characteristic of coating. The resistance to separation of coating from the substrate is defined as adhesion.

\section{Result and Discussion}

By varying the ration of MMA and $\mathrm{BA}$, the initial gloss level was not affected, however better gloss retention was found with 45:55 monomer ratio. The partial substitution of MMA with styrene resulted in improved initial gloss (Table-I).

1. Effect of post addition of MMA in 55:45 (BA:MMA) monomer composition: It had an adverse effect on paint stability and initial paint gloss.

2. Effect of initiator level in 50:50 (BA:MMA) monomer composition: By reducing the level of the initiator, water resistance and elongation at $\mathrm{F}$ max of emulsion film, some improvements in gloss level and paint opacity was observed.

3. Effect of initiator level in 55:45 (BA:MMA) monomer composition: By reducing the initiator level, the viscosity and freeze-thaw stability of the emulsion, some improvement was found in gloss retention while the decay of initial gloss level was found.

4. Effect of incorporation of glycerdyl methacrylate in 50:50 (BA:MMA) monomer composition: Incorporation of GMA helped in enhanced initial gloss level, whereas gloss retention was poor. Scrub resistance was also reduced.

5. Effect of incorporation of N-methylol acrylamide (NMA) in 50:50 (BA:MMA) monomer composition: By incorporation of NMA, the improvement in the initial gloss level was observed but gloss retention was found to be poor.

6. Effect of anionic surfactant in 50:50 (BA:MMA) monomer composition: By increasing the amount of anionic surfactant, 
ESSENCE_-IJERC | Jaspal et al. (2018) | IX (1): 55-60

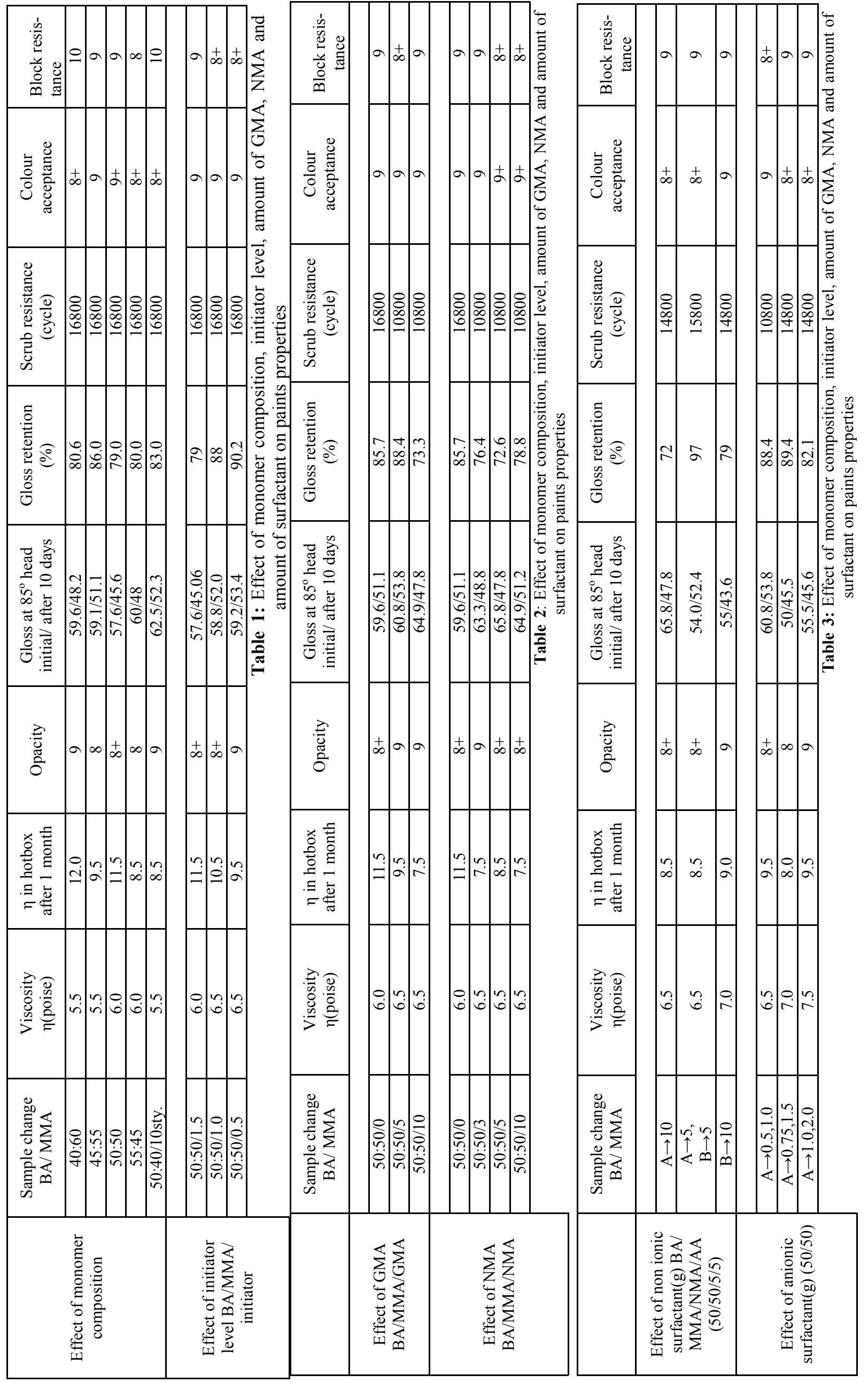


properties and paint properties.

7. Effect of NMA in different monomer composition with anionic surfactant: The gloss level of paint was reduced by the incorporation of NMA.

8. Effect of acrylic acid (AA) in $50: 50 / 5 \mathrm{~g}$ (BA:MMA/MMA) monomer composition: By reducing the amount of acrylic acid, the gloss level was reduced while gloss retention increased.

\section{Conclusion}

The work has shown that there was a good compatibility between the pigment and the binder during the paint formulation, which accounts for the deeper colour and good opacity for paints formulated. Characterization of the physico-chemical properties of the paints indicated good properties associated with the paints such as, good opacity, weathering resistance, excellent light fatness and quick drying. The paints were also found to have moderate viscosity which accounts for good flow properties.

The semi continuous emulsion polymerization of methyl methacrylate and butyl arylate using mixed surfactant system leads to increase in initial gloss of paints. The amount of surfactant have a significant effect on initial gloss and good block resistance in 50:50 (BA:MMA) monomer composition.

\section{References}

Abdulsalam, S. and Yahaya, Y. U. (2010): Effectiveness of Gum Arabic as a Binder in Emulsion House Paint. Glob. J. Eng. Res. 10:83-89.

Aggarwal, L. K.; Thapliyal, P. C. and Karade, S. R. (2007): Properties of polymer-modified mortars using epoxy and acrylic emulsions. Constr. Build. Mater, 21(2):379-383.

Alexander, A. E. and Napper, D. H. (1971): Emulsion polymerization. In: Jensen DP, editor. Progress in polymer science. Oxford: Pergamon Press;145-97.

Candau, F. (1999): Polymerization in microemulsions. In: Kumar P, Mittal KL, editors. Handbook of microemulsion science and technology. New York: Marcel Dekker, 679-712.

Capek, I. (1999): Microemulsion polymerization of styrene in the presence of anionic emulsifier. Adv. Colloid Interface Sci. 82:253-73.

Chern, C. S. (2002): Polymerization of monomer emulsions. In: Hubbard A, editor. Encyclopedia of surface and colloid science. New York: Marcel Dekker, 4220-4241.

Chern, C. S. (2003): Microemulsion polymerization. In: Encyclopedia of polymer science and technology.

Chu, H. and Lin, C. (1992): The stabilization effect of mixed-surfactants in the emulsion polymerization of $n$-butyl acrylate. Polym. Bull, 28:419.

Emelie, B.; Pichot, C. and Guillot, J. (1985): Batch emulsion copolymerization of n-butyl acrylate and methyl methacrylate in the presence of a nonionic surfactant. Makromol. Chem. Phy, 10:43-57.

$\mathrm{Fu}, \mathrm{H}$. and You-nian, L. (1998): Modification of acrylic electrophoretic coating by isocyanate. J. Cent. South Uni. Technol, 29(5):505-507.

Gan, L. M.; Chew, C. H.; Ng, S. C. and Loh, S. E. (1993): Polymerization of methyl methacrylate in ternary systems: emulsion and microemulsion. Langmuir. 9:2799.

Leonardi, F.; Derail, C. and Marin, G. (2005): Some applications of molecular rheology: Polymer formulation and molecular design. J. Non-Newton. Fluid Mech, 128(1), 50-61.

Li, B. and Brooks, B. W. (1992): Semi-batch processes for emulsion polymerization. Polym. Int. 29:41-46.

Li-jun, C.; Feng-qin, W.; Dong-shuang L.; Jian, Y. and Rong-xian, L. (2008): Preparation of self-crosslinked acrylate emulsion with high elasticity and its rheological properties. J. Cent. South Uni. Technol,15:324-328.

Moriguchi, N.; Tsugaru, T. and Amiva, S. (1999): Molecular design of the polymer forming the complex with metal (I): Design of the hardsegments of thermoplastic elastomers by using model compounds. J. Mol. Struct, 477, 191199.

Nomura, M.; Tobita, H. and Suzuki, K. (2005): Emulsion polymerization: kinetic and mechanistic aspects. Adv. Polym. Sci. 175:1-128. 
Poehlein, G. W. and Dougherty, D. J. (1977): Continuous emulsion polymerization. Rubber Chem. Technol, 50:601-638.

Tian-ying, G.; Xi, C.; Guang-jie, H.; Mou-dao, S. and Bang-hua, Z. (2005): Preparation and properties of room temperature self-crosslinking poly (MMA-co-BA-co-St-co-VTES) latex film. Adv. Polym. Technol,24(4):288-295.

Tian-ying, G.; Xi, C.; Mou-dao, S. and Bang-hua, Z. (2006): Preparation and properties of core (poly (styrene-n-butyl acrylate)]-shell (poly(styrenemethyl methacrylate-vinyl triethoxide silane)] structured latex particles with self-crosslinking characteristics. J. Appl. Polym. Sci, 100 (3):1824-1830.

Ugelstad, J. and Hansen, F. K. (1976): Kinetics and mechanism of emulsion polymerization. Rubber Chem. Technol, 49:536-609.

Vanderhoff, J. W. (1985): Mechanism of emulsion polymerization. J. Polym. Sci. Polym. Symp, 72:161-98.

Wang, Q.; Fu, S. and Yu, T. (1994): Emulsion polymerization. Prog. Polym. Sci, 19:703-753.

Yan-jun, C.; Chao-can, Z.; Yi-feng, W.; Shi-yuan, C. and Pei-zhi, C. (2003): Study of selfcrosslinking acrylate latex containing fluorine. J. Appl. Polym. Sci, 90(13): 3609-3616. 